\title{
JOINING OF Cu TO SS304 BY MICROWAVE HYBRID HEATING WITH Ni AS INTERLAYER
}

\author{
S. Tamang ${ }^{1}$, S. Aravindan ${ }^{1}$ \\ ${ }^{1}$ InstituteIndian Institute of Technology Delhi, Department of Mechanical Engineering, \\ Hauz Khas, New Delhi \\ aravindan@mech.iitd.ac.in
}

Keywords: microwave heating, $\mathrm{Cu}, \mathrm{SS} 304$, joining, $\mathrm{Ni}$

\begin{abstract}
Joining of dissimilar pure Copper $(\mathrm{Cu})$ to Stainless Steel (SS304) is necessitated in many industrial applications such as heat exchangers and electrical contacts. Advantages of both the materials such as high electrical conductivity of copper and better corrosion resistance of SS304 can be harnessed by way of joining both the metals. However, joining to $\mathrm{Cu}$ to itself or other materials is a challenge since the input heat is dissipated rapidly. Most of the conventional welding methods such as arc and gas are incompetent and unconventional methods such as Explosion Welding, EBW, and Diffusion Bonding are very expensive.

In this study a new economical process of joining of dissimilar metals i.e. $\mathrm{Cu}$ to SS304 by microwave hybrid heating is investigated. Microwave joining is made possible by applying a powder (in this work, Nickel metal powder) as an interlayer and exposing to microwave surrounding the interlayer with a susceptor.

The interlayer of $\mathrm{Ni}$ powder having average size $200 \mathrm{~nm}$ and $45 \mu \mathrm{m}$ was used. The microstructure of the joint was studied by optical microscope and scanning electron microscope. The joints formed with $200 \mathrm{~nm} \mathrm{Ni}$ powder were observed to have a defect free microstructure. The EDS and XRD analysis determine the formation of solid solution between $\mathrm{Cu}-\mathrm{Ni}$ interface and an intermetallic compound at $\mathrm{Fe}-\mathrm{Ni}$ interface. The diffusion of elements across the joint was further analyzed by EDS line scan. The hardness variation was studied by Vickers' micro-hardness. It can be concluded that smaller size Ni heats up faster in microwave and produce stronger joint of $\mathrm{Cu}$ to $\mathrm{SS} 304$ by microwave hybrid heating.
\end{abstract}

\section{Introduction}

Dissimilar material joining is gaining interest nowadays due to the application potentials in terms of flexibility, functionality and energy savings. Different industries such as chemical, nuclear, automobile, rail, aviation, electronics and power have requirements for dissimilar material joining. Many difficulties that occur during dissimilar joining are due to the difference in mechanical, thermal and electrical properties of the materials to be joined. Failures to join dissimilar combinations are due to the difference in thermal expansion coefficients, fusion zone (FZ) solidification or thermal fatigue. Bimetallic corrosion may also occur. Hence, it is difficult to fabricate dissimilar material combinations using conventional welding methods like Shielded Metal Arc Welding (SMAW), Gas Tungsten Arc Welding (GTAW), Gas Metal Arc Welding (GMAW), and Submerged Arc Welding (SAW) etc. There are other methods for making dissimilar joints such as explosive welding, laser welding, electron beam welding, diffusion bonding, brazing, soldering and friction welding. These methods follow stringent processing conditions, and are expensive and time consuming. Faster processing method is always the necessity of the industry owing to energy saving and improved productivity. 
Microwaves are the part of the electro-magnetic spectrum having wavelength between $1 \mathrm{~m}$ to $1 \mathrm{~mm}$ for frequencies ranging from $300 \mathrm{MHz}$ to $300 \mathrm{GHz}$. Faster and selective heating and energy saving are the well-known advantages of microwave processing [1]. The molecules interact with the microwaves and coverts the microwave energy to heat energy. Due to this, the materials heat up faster compared to conventional heating. On the other hand, in conventional heating the convection, conduction and radiation help in heating a sample from outside to inside. Microwave heating is used in the past for a number of applications such as heating fruits, beans, meat and cooking food. It is also used in other industries to dry paper, tobacco, leather, textiles, ceramics, cure adhesives, vulcanise rubber, waste management and etch semiconductors ${ }^{[2]}$ and in processing of ceramics, polymers and metals $^{[3]}$.

It is a well-known fact that metals reflect back most of the incident microwaves and penetration depth is limited to some microns. But when metals are used in powdered form it will heat up when subjected to microwave due to its small particle size being nearly equal to the penetration depth ${ }^{[4],[5]}$. The heating metal powders by microwaves was first reported by Walkiewicz et al ${ }^{[6]}$ of heating $\mathrm{Mg}, \mathrm{Fe}$ upto $120^{\circ} \mathrm{C}$ and $768^{\circ} \mathrm{C}$ respectively. Later Roy et al ${ }^{[7]}$ in 1999 conducted sintering to obtain full density components from metal powders with the formation of finer microstructures. This had resulted in better properties at lower cost.

Joining by microwave hybrid heating of similar bulk metals have been done by some researchers ${ }^{[8]-[15]}$. Limited work on dissimilar metals has been reported i.e. Srinath et al ${ }^{[16]}$ joined Stainless steel to mild steel and Bansal et al ${ }^{[17]}$ joined Inconel718 to SS316L.

The joining of copper and stainless steel can be used in many applications like in heat exchangers where corrosive fluids are used. The high conductivity of copper is a boon and a bane when it is to be joined with other material. Hence many problems are to be surpassed when welding copper to stainless steel. Tungsten inert gas (TIG) welding of copper is a challenge due to its high conductivity since all the heat generated is dissipated towards the base metal very fast. Copper has low miscibility with iron and no intermetallic compounds are expected. With preheating, TIG welding of the $\mathrm{Cu}$ and SS sheet is possible but with non-homogeneous joints, owing to resolidification time ${ }^{[18]}$. The high cooling rates in TIG and Electron beam welding cause bulk cooling of the molten pool. The molten metal solidifies to form $\mathrm{Fe}$ rich spherulites embedded in $\varepsilon-\mathrm{Cu}$ matrix and $\mathrm{Cu}$ rich spherulites embedded in $\alpha-\mathrm{Fe}$ matrix ${ }^{[18]}$. These phases will tend to transform to equilibrium microstructure on application of thermal stress during service life, thereby affecting the mechanical and corrosion properties of the joint ${ }^{[19]}$. Magnabosco et al ${ }^{[20]}$ confirmed the formation of non-equilibrium phases which are rich in $\mathrm{Cu}$ and $\mathrm{Fe}$ with $\mathrm{Fe}-\mathrm{Cr}-\mathrm{Ni}$ phase. The porosities in the copper-rich phase is due to the shrinkage of copper from inside the steel globule and intergranular microfissures at the interface towards the stainless steel are reported.

Diffusion welding was used to join $\mathrm{Cu}$ to SS304 by Yilmaz et al ${ }^{[21]}$. Micro-voids are seen along the grain boundaries on the $\mathrm{Cu}$ side of the bond region and it also has microcracks. Fracture can be observed at the microvoids on the copper side rather than the interface of $\mathrm{Cu}$ to SS. It is also reported that there is a thick band of intermetallic compounds formation. This is the limitation of the diffusion bonding process that leads to reduced joint strength. Using the same diffusion bonding process with nickel as an interlayer Sabetghadam et al [22] reported voids at both interfaces, that were of corrugated pattern. Intermetallic compounds were formed and its extent increased with temperature.

Explosion welding of $\mathrm{Cu}$ and stainless steel enhanced the tensile shear strength and flexural strength of joints ${ }^{[23]}$. Intermetallic compounds are not formed at the interface but the hardness is increased due collision of two plates. This process faces the limitation of being expensive and the lack in joint configuration flexibility. Moreover, it can be applied 
only to lap joint. Friction welding is another process used for joining copper to Stainless steel but this too is limited only to joining of cylindrical work piece. Sahin ${ }^{[24]}$ reported that the tensile strength of joint to be proportionally dependent on friction time and friction pressure until a certain point $(75 \mathrm{MPa})$ after which intermetallic compounds were observed to be formed at prolonged friction time.

By assembling a slope butt (scarf assembly) joint and focussing the laser on the steel side Yao et al ${ }^{[25]}$ achieved joint of $\mathrm{Cu}$ to $\mathrm{SS}$ with good tensile strength. Defect free joints can be obtained when limited copper is dissolved in steel matrix.

Hence it can be observed that there is a need of a joining process that can give good metallurgical joint with flexibility in joint configurations. Joining of Copper to Stainless Steel using microwave hybrid heating followed by analysis of the joints are presented in the subsequent sections.

\section{Materials and Methods}

Stainless steel SS304 and pure copper plates were cut into small section $6 \mathrm{~mm} \times 7 \mathrm{~mm} \times$ $25 \mathrm{~mm}$. Pure Nickel powder of average size $45 \mu \mathrm{m}$ and $200 \mathrm{~nm}$ was mixed with $20 \mathrm{wt} \%$ epoxy resin (bisphenol A diglycidyl ether) to form a slurry. The joint prepared was a simple lap joint with the prepared slurry in between as interlayer and clamped by a force $\sim 15 \mathrm{MPa}$ as observed in previous work ${ }^{[26]}$. A graphite crucible is placed inside a multimode microwave oven with $2.45 \mathrm{GHz}$ frequency and $3200 \mathrm{~W}$ power rating with the power set to $40 \%$. The sample is placed in top of graphite crucible and covered with graphite susceptor and microwave is set with a heating rate of $50^{\circ} \mathrm{C}$ per min.

\section{Results and Discussion}

The microstructure of the joints formed by $45 \mu \mathrm{m}$ and $200 \mathrm{~nm}$ Ni powder were observed under optical microscope. Fig. 1(a,b) clearly shows that the thickness of the interlayer using $45 \mu \mathrm{m} \mathrm{Ni}(140-170 \mu \mathrm{m})$ is larger than the interlayer formed by $200 \mathrm{~nm}$ Ni powder $(30-50 \mu \mathrm{m})$. It also contains voids which are not observed for the smaller Ni powder. This difference in interlayer thickness is due to the large difference in size of the powder which also affects the heating rate.

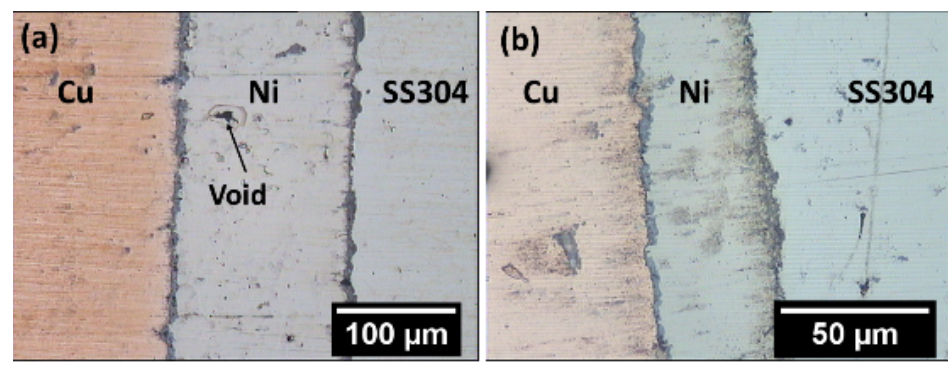

Fig. 1. Optical micrograph of the microwave joined $\mathrm{Cu}$ to SS034 samples (a) $45 \mu \mathrm{m} \mathrm{Ni}$ (b) $200 \mathrm{~nm}$ Ni powder

The experimental details are shown in Table 1 . The $200 \mathrm{~nm}$ Ni powder coupled with microwave at a soaking temperature of $900^{\circ} \mathrm{C}$ and $5 \mathrm{~min}$ soaking time. Microwave uniformly heat the metal powder if its size is smaller than the skin depth ${ }^{[27]}$. So the heating of metal powder depends on the skin depth,

$$
d=\sqrt{1 / \pi f \mu_{0} \mu^{r} \sigma}
$$


Where, $\sigma=$ electrical conductivity of a material $(\mathrm{S} / \mathrm{m})$

$f=$ frequency of the microwave $(\mathrm{Hz})$,

$\mu_{\circ}=$ permeability of free space and

$\mu^{\prime}=$ permeability $(\mathrm{H} / \mathrm{m})$.

Table 1. Experiment with varying temperature

\begin{tabular}{|c|c|c|c|c|c|c|c|}
\hline Size of & \multicolumn{2}{|c|}{ Soak time at $700{ }^{\circ} \mathrm{C}$} & \multicolumn{2}{|c|}{ Soak time at $800^{\circ} \mathrm{C}$} & \multicolumn{3}{|c|}{ Soak time at $900^{\circ} \mathrm{C}$} \\
\hline & $5 \mathrm{~min}$ & $10 \mathrm{~min}$ & $5 \mathrm{~min}$ & $10 \mathrm{~min}$ & $5 \mathrm{~min}$ & $10 \mathrm{~min}$ & $15 \mathrm{~min}$ \\
\hline $45 \mu \mathrm{m}$ & No joint & No joint & No joint & No joint & $\begin{array}{c}\text { No } \\
\text { joint }\end{array}$ & $\begin{array}{c}\text { No } \\
\text { joint }\end{array}$ & $\begin{array}{c}\text { Good } \\
\text { Joint }\end{array}$ \\
\hline $200 \mathrm{~nm}$ & No joint & No joint & No joint & No joint & $\begin{array}{l}\text { Good } \\
\text { Joint }\end{array}$ & $\begin{array}{c}\text { Good } \\
\text { Joint }\end{array}$ & $\begin{array}{c}\text { Good } \\
\text { Joint }\end{array}$ \\
\hline
\end{tabular}

Thus 200nm Ni powder heat up faster by microwave hybrid heating than $45 \mu \mathrm{m}$ Ni powder. The SEM image of the joints representing the different points across them are shown in Fig.2. The elements present on all these points are represented in Table 2. From the EDS data, the diffusion of $\mathrm{Cu}$ and $\mathrm{Fe}$ across the interlayer is very prominent in addition to some diffusion of $\mathrm{Ni}$ and $\mathrm{Cr}$. Since $\mathrm{Ni}$ and $\mathrm{Cu}$ are fully soluble ${ }^{[28]}$ in each other and diffusion of $\mathrm{Cu}$ is high. The interlayer forms into a solid solution of $\mathrm{Ni}$ and $\mathrm{Cu}$ by substitution method. A reaction layer of $\mathrm{FeNi}_{3}$ is formed between $\mathrm{SS} 304$ and the $\mathrm{Ni}$ interlayer. The higher diffusion of $\mathrm{Cu}$ and $\mathrm{Fe}$ for $200 \mathrm{~nm}$ Nickel is due to the faster heating obtained by the smaller size of the powder particle. The XRD analysis of the joint cross-section verify the formation of $\mathrm{FeNi}_{3}$ also represented in Fig 3.
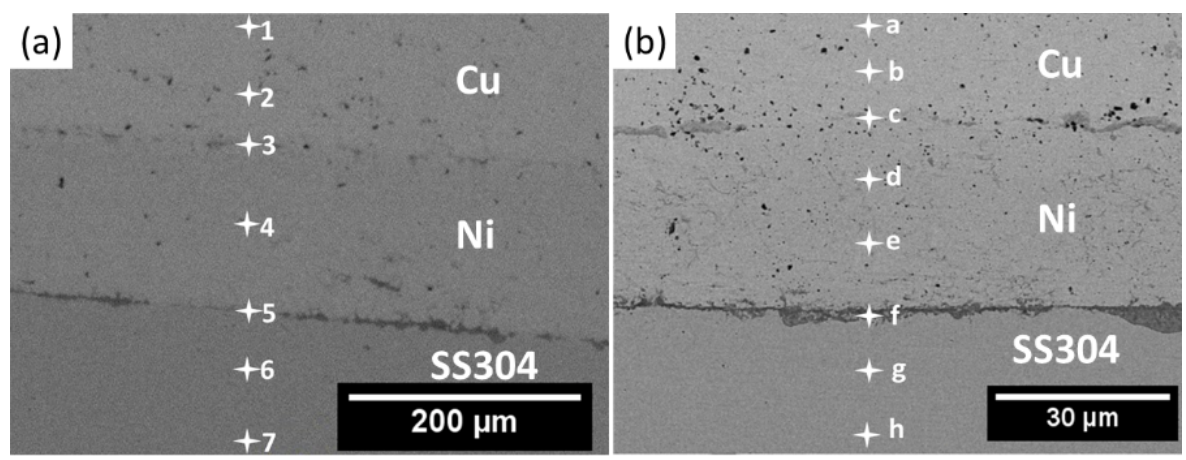

Fig 2. The SEM image of (a) $45 \mu \mathrm{m} \mathrm{Ni}$ and (b) $200 \mathrm{~nm}$ Ni powder 


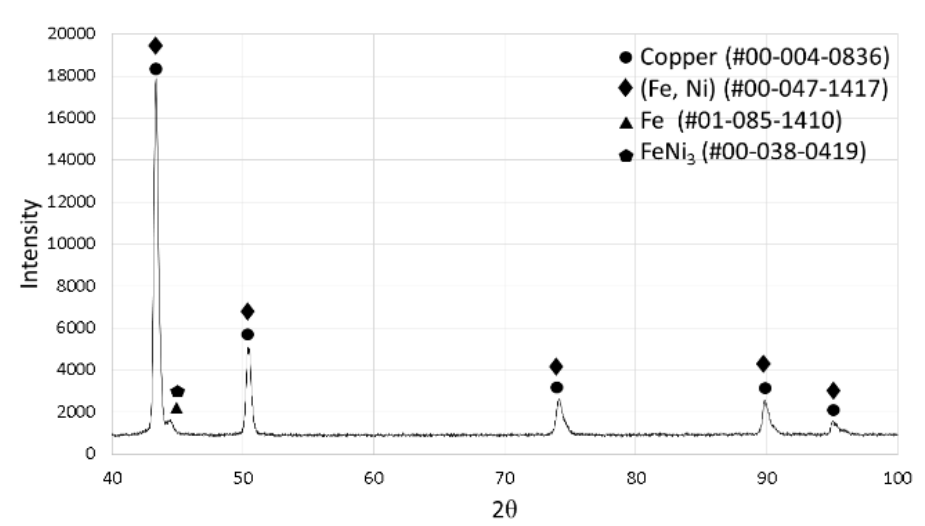

Fig. 3.XRD analysis across the joint zone

Table 2. wt $\%$ of elements obtained by EDS of points shown in Fig 2

\begin{tabular}{|c|c|c|c|c|c|c|c|}
\hline & Point & $\mathrm{O}$ & $\mathrm{Cr}$ & $\mathrm{Fe}$ & $\mathrm{Ni}$ & $\mathrm{Cu}$ & Probable compound \\
\hline \multirow{7}{*}{$\begin{array}{c}45 \\
\mu \mathrm{m}\end{array}$} & 1 & 1.333 & 0.794 & 2.144 & 2.430 & 93.299 & $\mathrm{Cu}$ \\
\hline & 2 & 1.278 & 0.806 & 2.388 & 2.961 & 92.567 & $\mathrm{Cu}$ \\
\hline & 3 & 1.367 & 1.088 & 2.730 & 26.939 & 67.875 & $\mathrm{Ni}-\mathrm{Cu}$ solid solution \\
\hline & 4 & 0.378 & 1.273 & 4.050 & 60.579 & 33.719 & $\mathrm{Ni}-\mathrm{Cu}$ solid solution \\
\hline & 5 & 5.027 & 5.114 & 18.994 & 39.760 & 31.106 & $\mathrm{FeNi}_{3}+\mathrm{Cu}$ \\
\hline & 6 & 1.473 & 14.436 & 51.843 & 9.252 & 22.996 & SS304 \\
\hline & 7 & 0.653 & 15.197 & 53.531 & 8.850 & 21.769 & SS304 \\
\hline \multirow{8}{*}{$\begin{array}{l}200 \\
\mathrm{~nm}\end{array}$} & $\mathrm{~A}$ & 0.605 & 1.218 & 4.323 & 2.692 & 91.162 & $\mathrm{Cu}$ \\
\hline & $\mathrm{B}$ & 0676 & 1.197 & 4.538 & 4.051 & 89.537 & $\mathrm{Cu}$ \\
\hline & $\mathrm{C}$ & 2.689 & 1.414 & 4.989 & 19.949 & 70.958 & $\mathrm{Ni}-\mathrm{Cu}$ solid solution \\
\hline & $\mathrm{D}$ & 1.051 & 1.431 & 5.642 & 56.196 & 35.680 & $\mathrm{Ni}-\mathrm{Cu}$ solid solution \\
\hline & $\mathrm{E}$ & 2.951 & 1.763 & 10.683 & 53.302 & 31.301 & $\mathrm{Ni}-\mathrm{Cu}$ solid solution \\
\hline & $\mathrm{F}$ & 4.677 & 4.372 & 20.102 & 40.006 & 30.843 & $\mathrm{FeNi}_{3}+\mathrm{Cu}$ \\
\hline & $\mathrm{G}$ & 1.572 & 14.786 & 50.177 & 6.901 & 26.564 & SS304 \\
\hline & $\mathrm{H}$ & 0.914 & 14.219 & 54.203 & 6.665 & 23.999 & SS304 \\
\hline
\end{tabular}

The Microhardness across the two types of joint obtained after soaking at $900^{\circ} \mathrm{C}$ for $15 \mathrm{~min}$ was measured as represented in Fig 4. The hardness of the Ni-Cu solid solution is higher for $200 \mathrm{~nm}$ powder than $45 \mu \mathrm{m}$. The hardness of the heat affected zone is also higher for $200 \mathrm{~nm}$ powder. With decrease in metal powder size the heating rate of the Ni interlayer increases and also reaches a higher temperature. All this is attributed due to total necking and melting of nano Ni powder. The lower hardness of $45 \mu \mathrm{m}$ is due to the partial fusion of the interlayer and presence of pores. 

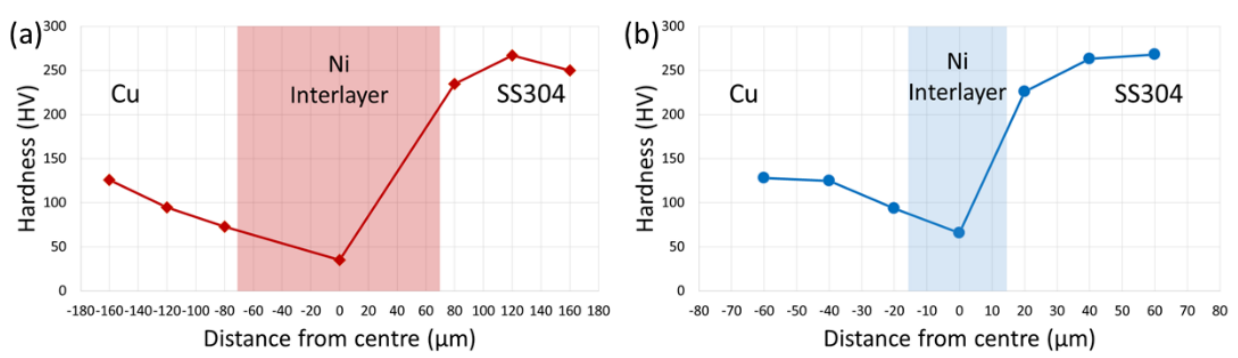

Fig. 4. Microhardness of the joint cross-section with joints formed using (a) $45 \mu \mathrm{m}$ size Ni powder and (b) $200 \mathrm{~nm}$ size Ni powder

\section{Conclusion}

The following conclusion are made for the study of joining of $\mathrm{Cu}$ to SS304 by microwave hybrid heat using Ni metal powder:

1. The joining was successful by using both $45 \mu \mathrm{m}$ and $200 \mathrm{~nm}$ Ni metal powder as interlayer

2. The $200 \mathrm{~nm}$ Ni formed the joint faster than $45 \mu \mathrm{m} \mathrm{Ni}$.

3. The thickness of the interlayer formed by $200 \mathrm{~nm} \mathrm{Ni}$ is almost 3 times smaller than the formed by $45 \mu \mathrm{m}$.

4. The microhardness of the interlayer is higher for the $200 \mathrm{~nm} \mathrm{Ni}$, with porosity in turn exhibiting higher strength.

\section{References}

1. Siores, E. \& Do Rego, D. Journal of Materials Processing Technology, 1995, 48, 619-625.

2. Clark, D. E. \& Sutton, W. H. Annual reviews Matterial Science, 1996, 26, 299331.

3. Thostenson, E. T. \& Chou, T. W. Composites Part A: Applied Science and Manufacturing , 1999, 30, 1055-1071.

4. Sheinberg, H., Meek, T. T. \& Blake, R. D. Patent Number: 4,942,278, 1990, 1-3.

5. Huey, H. E. \& Morrow, M. S. in Fourth World Congress on Microwave and Radio Frequency Applications (eds. Schulz, R. L. \& Folz, D. C.) , 2004, 286-293.

6. Walkiewicz, J. W., Kazonich, G. \& McGill, S. L. in Mineral Metallurgy Proceedings 5, 1988, 39-42.

7. Roy, R., Agrawal, D., Cheng, J. \& Gedevanlshvili, S. Nature , 1999, 399, 668670.

8. Srinath, M. S., Sharma, A. K. \& Kumar, P. Materials \& Design, 2011, 32, 26852694.

9. Srinath, M. S., Sharma, a. K. \& Kumar, P. Proceedings of the Institution of Mechanical Engineers, Part B: Journal of Engineering Manufacture, 2011, 225, 1083-1091. 
10. Srinath, M. S., Murthy, P. S., Sharma, A. K., Kumar, P. \& Kartikeyan, M. V. International Journal of Engineering, Science and Technology, 2012, 4, 152-158.

11. Badiger, R. I., Narendranath, S. \& Srinath, M. S. Journal of Manufacturing Processes , 2015, 18, 117-123.

12. Bansal, A., Sharma, A. K., Kumar, P. \& Das, S. Materials Characterization, 2014, 91, 34-41.

13. Bansal, A., Sharma, A. K., Kumar, P. \& Das, S. JOM , 2015, 67, 2087-2098.

14. Singh, S., Suri, N. M. \& Belokar, R. M. Materials Today: Proceedings , 2015, 2, 1340-1346.

15. Gupta, P., Kumar, S. \& Kumar, A. Materials and Manufacturing Processes , 2013, 28, 601-604.

16. Srinath, M. S., Sharma, A. K. \& Kumar, P. Journal of Manufacturing Processes , 2011, 13, 141-146.

17. Bansal, A., Sharma, A. K., Das, S. \& Kumar, P. Proceedings of the Institution of Mechanical Engineers, Part L: Journal of Materials Design and Applications, 2015, 1-10.

18. Munitz, A. Journal of Materials Science, 1995, 30, 2901-2910.

19. Tosto, S., Nenci, F., Jiandong, H., Corniani, G. \& Pierdominici, F. Material Science and Technology, 2003, 19, 519-522.

20. Magnabosco, I., Ferro, P., Bonollo, F. \& Arnberg, L. Materials Science and Engineering A , 2006, 424, 163-173.

21. Yilmaz, O. Journal of Materials Processing Technology, 2003, 141, 67-76.

22. Sabetghadam, H., Hanzaki, A. Z. \& Araee, A. Materials Characterization, 2010, 61, 626-634.

23. Durgutlu, A., Gülenç, B. \& Findik, F. Materials and Design, 2005, 26, 497-507.

24. Sahin, M. Industrial Lubrication and Tribology, 2012, 61, 319-324.

25. Yao, C. et al. Optics and Lasers in Engineering , 2009, 47, 807-814.

26. Tamang, S. \& Aravindan, S. Journal of Manufacturing Processes , 2017, 28, 94 100.

27. Mishra, R. R. \& Sharma, A. K. Critical Reviews in Solid State and Materials Sciences , 2016, 41, 217-255.

28. Baker, H. Alloy Phase Diagrams. ASM Handbook, 1998. 